\title{
Analisis Perbandingan Metode Fuzzy Mamdani Dan Fuzzy Sugeno Untuk Penentuan Kualitas Cor Beton Instan
}

\author{
Supina Batubara \\ Fakultas Ilmu Komputer, Universitas Pembangunan Panca Budi Medan, Jalan Jenderal Gatot \\ Subroto KM. 4,5 Sei Sikambing 20122 Kota Medan, Sumatera Utara, Indonesia \\ E-mail: pinazien@gmail.com
}

\begin{abstract}
The rapid growth of knowledge and technology in the field of construction that encourages people to pay more attention to quality standards and work productivity to be able to participate in improving a construction with a higher quality. Needed a building material that has a better advantage than existing building materials so far. If the concrete used has a low quality then it can cause the building that was built can not last long. For that we need a method used in accelerating determine the quality of concrete. To ensure the method used then the comparison of Fuzzy logic method Mamdani and Sugeno method so that later produced a method that best suits in determining the quality of concrete. Fuzzy logic is different from ordinary digital logic, where the usual digital logic only recognizes two states ie yes or no. While Fuzzy logic mimics the way of human thinking by using the concept of the pseudonym of a value.
\end{abstract}

Keywords: Fuzzy Logic, Mamdani, Sugeno, Instant Instant Concrete Quality

\begin{abstract}
Abstrak
Semakin pesatnya pertumbuhan pengetahuan dan teknologi di bidang konstruksi yang mendorong masyarakat lebih memperhatikan standar mutu serta produktivitas kerja untuk dapat berperan serta dalam meningkatkan sebuah pembangunan konstruksi dengan lebih berkualitas. Diperlukan suatu bahan bangunan yang memiliki keunggulan yang lebih baik dibandingkan bahan bangunan yang sudah ada selama ini. Jika beton yang digunakan memiliki kualitas rendah maka dapat menyebabkan bangunan yang dibangun tidak dapat bertahan lama. Untuk itu diperlukan suatu metode yang digunakan dalam mempercepat menentukan kualitas beton. Untuk memastikan metode yang digunakan maka dilakukanlah perbandingan logika Fuzzy metode Mamdani dan metode Sugeno sehingga nanti dihasilkan sebuah metode yang paling cocok dalam menentukan kualitas beton. Logika Fuzzy berbeda dengan logika digital biasa, di mana logika digital biasa hanya mengenal dua keadaan yaitu ya atau tidak. Sedangkan logika Fuzzy meniru cara berfikir manusia dengan menggunakan konsep sifat kesamaran suatu nilai.
\end{abstract}

Kata Kunci : Fuzzy Logic, Mamdani, Sugeno, Cor Beton Instan Quality

\section{PENDAHULUAN}

Semakin pesatnya pertumbuhan pengetahuan dan teknologi di bidang konstruksi yang mendorong masyarakat lebih memperhatikan standar mutu serta produktivitas kerja untuk dapat berperan serta dalam meningkatkan sebuah pembangunan konstruksi dengan lebih berkualitas. Diperlukan suatu bahan bangunan yang memiliki keunggulan yang lebih baik dibandingkan bahan bangunan yang sudah ada selama ini.Istilah Ready Mix Concrete/cor beton instan sudah tidak asing lagi di kalangan para Engineer, karena sudah hampir sebagian besar gedung-gedung dan sarana infrastruktur menggunakan beton sebagai bahan dasar dari bangunan. Beton merupakan komponen utama struktur bangunan 
yang terdiri atas semen, agregat kasar, agregat halus dan air dengan atau tanpa bahan tambahan. Sebagai material yang terbentuk secara kimiawi, maka aspek pabrikasi sangat berpengaruh terhadap kualitas akhir beton yang dihasilkan. Kemajuan pesat di bidang konstruksi harus diimbangi dengan kemajuan teknologi beton sebagai sarana pendukungnya. Teknologi yang diterapkan diharapkan dapat meminimalisir masalah yang terjadi di lapangan.Menurut SNI 03-443-1997 mendefinisikan beton cor instan adalah beton yang dicampur dalam suatu mesin pengaduk stasioner atau dalam truk pengaduk, dan diserahkan kepada konsumen beton dalam keadaan segar. Penggunaan beton pada gedung bisa menghemat pengeluaran karena harga yang terjangkau, dapat dibuat sesuai dengan bentuk dan ukuran yang diinginkan serta dapat dikombinasikan dengan baja tulangan. Rasa tertarik pada penggunaan beton ini akhirnya menimbulkan banyaknya jenis/mutu dari beton itu sendiri.

Logika Fuzzy dalam penerapan lainnya yaitu perbandingan Mamdani dan Sugeno untuk sistem resiko kanker payudara (Shleeg, A. A. dan Ellabib, I. M., 2013) serta penerapan tentang perbandingan metode Mamdani, Sugeno dan Tsukamoto untuk sistem pengurangan energi pada penyejuk udara (Saepullah dan Satria Wahono, 2015). Dalam jurnal dilakukan analisis dan perbandingan antara metode Mamdani, Sugeno dan Tsukamoto untuk menemukan metode terbaik dalam hal pengurangan konsumsi energi listrik dari AC dengan menggunakan suhu kamar dan kelembaban sebagai variabel masukan dan kecepatan kompresor sebagai output variabel. Hasil percobaan menunjukkan bahwa metode terbaik dalam hal pengurangan konsumsi energi listrik dari AC adalah metode Tsukamoto, dimana efisiensi energi listrik rata-rata yang dicapai hingga 74,2775\%.

\section{METODE PENELITIAN}

Kerangka kerja ini merupakan langkah-langkah yang akan dilakukan dalam penyelesaian masalah yang akan dibahas. Adapun kerangka kerja penelitian ini dapat digambarkan pada gambar 3 :

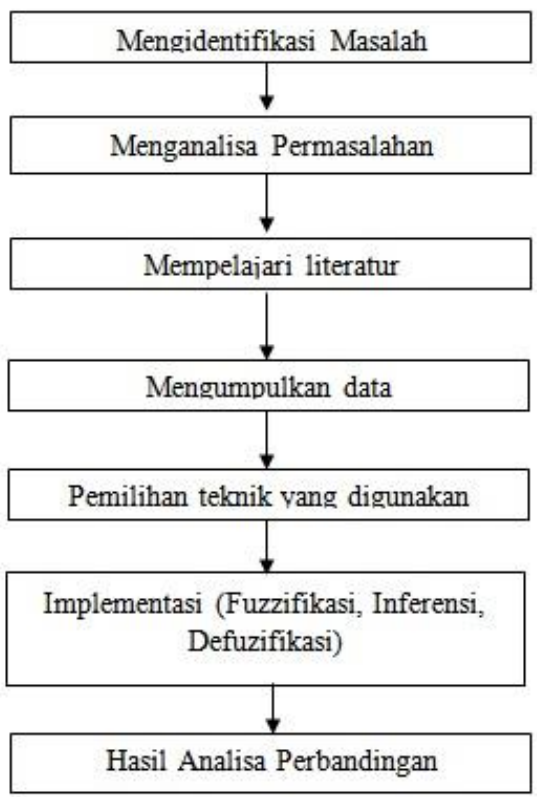

Gambar 1. Kerangka Kerja Penelitian 
(SNI 03-2834-1993) mendefenisikan beton adalah campuran anatara semen Portland atau semen hidrolik yang lain, agregat halus, agregat kasar dan air dengan atau tanpa bahan tambah membentuk massa padat. Proses awal terbentuknya beton adalah pasta semen yaitu proses hidrasi antara air dengan semen, selanjutnya jika ditambah dengan agregat halus menjadi mortar dan jika ditambahkan dengan agregat kasar menjadi beton. Penambahan material lain akan membentuk beton yang bermacam-macam seperti beton bertulang, beton serat, beton ringan, beton presstress, beton pracetak dan lainnya. Proses terbentuknya beton dapat dilihat pada gambar di bawah ini.

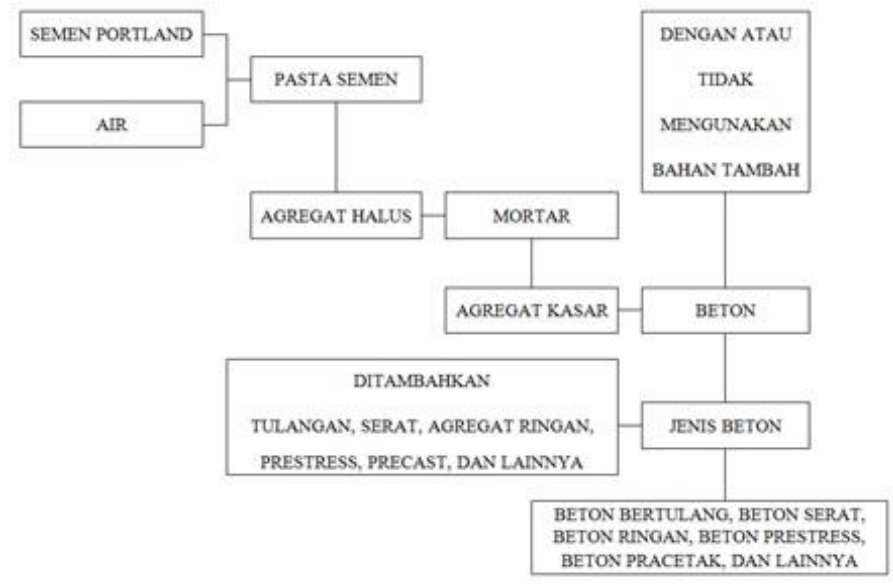

Gambar 2. Proses Terbentuknya Beton

Logika Fuzzy dikembangkan oleh Prof. Lotfi Zadeh dari Universitas California USA, pada tahun 1965. Zadeh memodifikasi teori himpunan, dimana setiap anggotanya memiliki derajat keanggotaan antara 0 sampai 1 yang disebut dengan himpunan kabur. Pada logika fuzzy sebuah nilai bisa benar dan salah secara bersamaan namun berapa besar nilai kebenaran dan kesalahan tergantung pada bobot keanggotaannya.

Sistem Fuzzy terdiri dari 4 komponen yaitu basis aturan Fuzzy, mesin inferensi Fuzzy, pembuat Fuzzy (fuzzifier), dan penegasan (defuzzifier) (Nur Hasanah dan Retantyo Wardoyo, 2010).

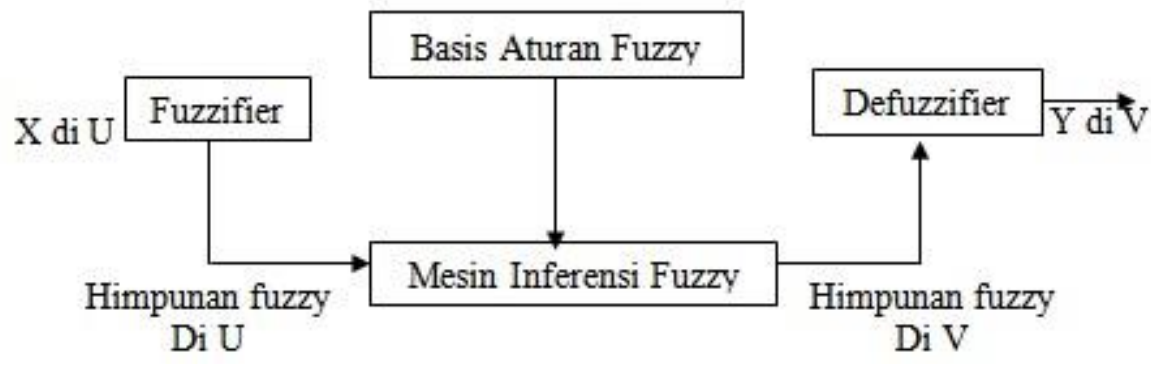

Gambar 3. Proses Terbentuknya Beton

Proses pada sistem Fuzzy yaitu dari input yang berupa data real diubah oleh fuzzifier (tahap fuzzifikasi) menjadi nilai Fuzzy di U kemudian diolah oleh mesin inferensi Fuzzy dengan aturan dasar Fuzzy yang selanjutnya ditegaskan kembali dengan defuzzifier (tahap defuzifikasi) menjadi nilai tegas (output). Dalam teori logika Fuzzy sebuah nilai bisa 
bernilai benar dan salah secara bersamaan namun berapa besar kebenaran dan kesalahan suatu nilai tergantung kepada bobot keanggotaan yang dimilikinya.

Metode Mamdani sering dikenal sebagai metode Max-min. Metode ini diperkenalkan oleh Ebrahim Mamdani pada tahun 1975. Untuk mendapatkan output, diperlukan 4 tahapan (Suamiati dan Shodik Nuryadin, 2013) :

- Pembentukan Himpunan Fuzzy

Pada metode mamdani, baik variabel input maupun variabel output dibagi menjadi satu atau lebih himpunan Fuzzy.

- Aplikasi Fungsi Implikasi

Pada metode mamdani, fungsi implikasi yang digunakan adalah min.

- Komposisi Aturan

Ada tiga metode yang digunakan dalam melakukan inferensi sistem Fuzzy, yaitu max, additive dan probabilistik OR (probor).

1. Metode Max (Maximum)

Pada metode ini, solusi himpunan Fuzzy diperoleh dengan cara mengambil nilai maksimum aturan, kemudian menggunakannya untuk memodifikasi daerah Fuzzy, dan mengaplikasikannya ke output dengan menggunakan operator OR (union). Jika semua proposisi telah dievaluasi, maka output akan berisi suatu himpunan Fuzzy yang mereflesikan konstribusi dari tiap-tiap proposi. Secara umum dapat dituliskan:

$\mu s f[x i]=\max (\mu s f[x i], \mu k f[x i])$

Di mana :

$\mu s f[x i]=$ nilai keanggotaan solusi Fuzzy sampai aturan ke- $i$.

$\mu k f[x i]=$ nilai keanggotaan konsekuen Fuzzy aturan ke- $i$.

2. Metode Additive (sum)

Pada metode ini, solusi himpunan Fuzzy diperoleh dengan cara melakukan bounded-sum terhadap semua output daerah Fuzzy. Secara umum dituliskan:

$\mu s f[x i]=\min (1, \mu s f[x i]+\mu k f[x i])$

Di mana:

$\mu s f[x i]=$ nilai keanggotaan solusi Fuzzy sampai aturan ke- $i$.

$\mu k f[x i]=$ nilai keanggotaan konsekuen Fuzzy aturan ke-i.

3. Metode Probabilistik OR (Probor)

Pada metode ini, solusi himpunan Fuzzy diperoleh dengan melakukan product terhadap semua output daerah Fuzzy. Secara umum dituliskan:

$\mu s f[x i]=(\mu s f[x i]+\mu k f[x i])-(\mu s f[x i] * \mu k f[x i]$

Di mana:

$\mu s f[x i]=$ nilai keanggotaan solusi Fuzzy sampai aturan ke- $i$.

$\mu k f[x i]=$ nilai keanggotaan konsekuen $F u z z y$ aturan ke- $i$.

\subsection{Penegasan (DeFuzzy)}

Input dari proses defuzzifikasi adalah suatu himpunan Fuzzy diperoleh dari komposisi aturan-aturan Fuzzy, sedangkan output yangdihasilkan merupakan suatu bilangan pada domain himpunan Fuzzy tersebut. Sehingga jika diberikan suatu himpunan 
Fuzzy dalam range tertentu, maka harus dapat diambil suatu nilai crisp tertentu sebagai output.

Ada beberapa metode defuzzifikasi pada komposisi aturan Mamdani, antara lain:

1. Metode Centroid (Composite Moment)

Pada metode ini, solusi crisp diperoleh dengan cara mengambil titik pusat $\left(\mathrm{z}^{*}\right)$ daerah Fuzzy. Secara umum dirumuskan:

Untuk variabel kontinu:

$$
z^{*}=\frac{\int_{a}^{b} z \mu(z) d z}{\int_{a}^{b} \mu(z) d z}
$$

Untuk variabel diskret:

$\mathrm{z}^{*}=\frac{\sum_{j=1}^{n} z j \mu(Z j)}{\sum_{j=1}^{n} \mu(Z j)}$

\section{Metode Bisektor}

Pada metode ini, solusi crisp diperoleh dengan cara mengambil nilai pada domain Fuzzy yang memiliki nilai keanggotaan setengah dari jumlah total nilai keanggotaan pada daerah Fuzzy.

\section{Metode Mean of Maximum (MOM)}

Pada metode ini, solusi crisp diperoleh dengan cara mengambil nilai rata-rata domain yang memiliki nilai keanggotaan maksimum.

\section{Metode Largest of Maximum (LOM)}

Pada metode ini, solusi crisp diperoleh dengan cara mengambil nilai terbesar dari domain yang memiliki nilai keanggotaan maksimum. Penalaran dengan metode Sugeno hampir sama dengan penalaran Mamdani, hanya saja output (konsekuen) sistem tidak berupa himpunan Fuzzy, melainkan berupa konstanta atau persamaan linear. Metode ini diperkenalkan oleh Takagi-Sugeno Kang pada tahun 1985, sehingga metode ini sering juga dinamakan dengan metode TSK.

Output dari sistem inferensi fzzy diperlukan 4 tahap (Suwandi et al, 2011) :

\subsection{Tahap Fuzzifikasi}

Fuzzifikasi merupakan proses mentransformasikan data pengamatan ke dalam bentuk himpunan Fuzzy.

1. Pembentukan aturan dasar data Fuzzy

Aturan dasar Fuzzy mendefinisikan hubungan antara fungsi keanggotaan dan bentuk fungsi keanggotaan hasil. Pada metode Sugeno output (konsekuen) sistem tidak berupa himpunan Fuzzy tetapi berupa konstanta atau persamaan linier. Metode TSK terdiri dari 2 jenis, yaitu:

a. Model Fuzzy Sugeno Orde-Nol

Secara umum bentuk model Fuzzy Sugeno orde-nol adalah 
$I F\left(x_{1}\right.$ is $\left.A_{1}\right) \cdot\left(x_{2}\right.$ is $\left.A_{2}\right) \bullet\left(x_{3}\right.$ is $\left.A_{3}\right) \cdot \ldots . . .\left(x_{N}\right.$ is $\left.A_{N}\right)$ THEN $z=k$

Dengan $\mathrm{A}_{\mathrm{i}}$ adalah himpunan Fuzzy ke-i sebagai anteseden, dan k adalah suatu konstanta (tegas) sebagai konsekuen.

b. Model Fuzzy Sugeno Orde-Satu

Secara umum bentuk model Fuzzy Sugeno Orde-Satu adalah

IF $\left(x_{1}\right.$ is $\left.A_{1}\right) \cdot \ldots \ldots .\left(x_{N}\right.$ is $\left.A_{N}\right)$ THEN $z=p_{1}{ }^{*} x_{1}+\ldots . .+p_{N}{ }^{*} x_{N}+q$

Dengan $\mathrm{A}_{\mathrm{i}}$ adalah himpunan Fuzzy ke-i sebagai anteseden dan $\mathrm{p}_{\mathrm{i}}$ adalah suatu konstanta (tegas) ke-i dan q juga merupakan konstanta dalam konsekuen.

2. Komposisi aturan

Apabila sistem terdiri dari beberapa aturan makan inferensi dari kumpulan dan korelasi antar aturan yaitu menghitung hasil.

\section{Penegasan (defuzzifikasi)}

Pada proses ini output berupa bilangan crisp. Apabila komposisi aturan menggunakan metode Sugeno, maka defuzifikasi dilakukan dengan cara mencari nilai rataratanya.

\section{HASIL DAN PEMBAHASAN}

Identifikasi untuk menentukan kualitas beton dilakukan dengan menentukan variabel yang diperlukan dalam pengolahan dan analisis, dimana variabel atau kriteria yang harus dipenuhi adalah agg halus, agg kasar, isi. Tabel 1 adalah data - data yang diambil dan diamati langsung ke tempat penelitian yang akan dipersentasikan serta yang akan dianalisa ke dalam bentuk metode Fuzzy Logic.

Tabel 1. Data Ready Mix Concrete / Beton

\begin{tabular}{|c|c|c|c|c|c|}
\hline \multirow{2}{*}{ No } & \multirow{2}{*}{ Nama } & \multicolumn{2}{|c|}{ Agg Halus } & \multicolumn{2}{c|}{ Agg Kasar } \\
\cline { 3 - 6 } & & Lumpur & Air & Lumpur & Air \\
\hline 1 & Sampel 01 & 5,13 & 7,68 & 1,11 & 1,82 \\
\hline 2 & Sampel 02 & 5,93 & 9,15 & 1,83 & 2,32 \\
\hline 3 & Sampel 03 & 3,82 & 6,55 & 1,52 & 1,45 \\
\hline 4 & Sampel 04 & 5,18 & 7,10 & 1,63 & 1,17 \\
\hline 5 & Sampel 05 & 6,59 & 7,45 & 1,39 & 2,59 \\
\hline 6 & Sampel 06 & 7,45 & 6,95 & 1,54 & 1,86 \\
\hline 7 & Sampel 07 & 5,23 & 7,76 & 0,79 & 1,57 \\
\hline 8 & Sampel 08 & 4,72 & 6,44 & 1,17 & 2,25 \\
\hline 9 & Sampel 09 & 4,63 & 7,33 & 1,12 & 2,45 \\
\hline 10 & Sampel 10 & 4,83 & 8,09 & 1,26 & 2,70 \\
\hline
\end{tabular}

Dalam menentukan perancangan sistem dengan menggunakan metode Mamdani atau metode Sugeno, terdapat 3 variabel input yaitu: agg halus kadar lumpur, agg halus 
kadar air, agg kasar kadar lumpur, agg kasar kadar airdan 1 variabel output yaitu variabel kualitas. hal ini dapat dilihat pada gambar berikut :



\section{Agg Kasar Kadar Air}

Gambar 4. Variabel Input \& Output Pada Metoda Mamdani

Pada gambar 4 dapat dilihat bahwa antara metode Mamdani dan metode Sugeno dalam menganalisa kualitas beton menggunakan variabel input yang sama yaitu agg halus, agg kasar dan berat isi sehingga tidak ada perbedaan antara fungsi keanggotaan untuk metode Mamdani dengan fungsi keanggotaan metode Sugeno. Untuk memperoleh output terdapat perbedaan metode Mamdani dengan metode Sugeno yaitu metode Mamdani berupa himpunan fuzzy sedangkan pada metode Sugeno berupa constanta atau persamaan linear. Dalam penelitian ini penulis menggunakan constanta atau berordo 0 untuk menghasilkan output metode Sugeno.

Fungsi keanggotaan kualitas beton berdasarkan agg halus kadar lumpur akan didesain terlebih dahulu fungsi keanggotaannya sebagai berikut :

$$
\begin{aligned}
& \text { Sedikit }[\mathrm{x} 1]= \begin{cases}1 ; & \mathrm{x} \leq 2 \\
(4-\mathrm{x}) /(4-2) & 2 \leq \mathrm{x} \leq 4 \\
0 ; & \mathrm{x} \geq 4\end{cases} \\
& \text { Sedang }\left[\mathrm{x}_{2}\right]=\left\{\begin{array}{lll}
0 ; & \mathrm{x} \leq 2 \text { atau } \mathrm{x} \geq 6 \\
(\mathrm{x}-2) /(4-2) & ; & 2 \leq \mathrm{x} \leq 4 \\
(6-\mathrm{x}) /(6-4) & ; & 4 \leq \mathrm{x} \leq 6
\end{array}\right. \\
& \text { Banyak }[\mathrm{x} 3]= \begin{cases}0 ; & \mathrm{x} \leq 4 \\
(\mathrm{x}-4) /(6-4) ; & 4 \leq \mathrm{x} \leq 6 \\
1 ; & \mathrm{x} \geq 6\end{cases}
\end{aligned}
$$

Gambar 5. Rentang Fungsi Keanggotaan

Dari persamaan di atas, bentuk fungsi keanggotaan fuzzynya digambarkan seperti tabel 2. Pada tabel 2 input pertama dari analisa fuzzy tentang analisa kualitas beton yang datanya masih samar sebagai dasar pengambilan keputusan untuk menentukan kualitas beton. 
Tabel 2. Data Ready Mix Concrete / Beton

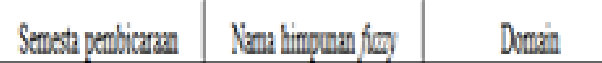
gambar 6.

Dari persamaan di atas, bentuk fungsi keanggotaan fuzzynya didesain seperti



Gambar 6. Model Input Untuk Agg Halus Kadar Lumpur

Defuzzifikasi untuk metode Mamdani yang digunakan dalam penelitian ini adalah metode centroid (Composite Moment) dimana solusi crips diperoleh dengan cara mengambil titik pusat $\left(\mathrm{z}^{*}\right)$ daerah fuzzy. Untuk metode Sugeno yang digunakan adalah model fuzzy sugeno Orde-Nol dimana outputnya berupa konstanta (tegas), untuk mendapatkan defuzzifikasinya dilakukan dengan cara mencari nilai rata-rata.

Pada implementasi dan pengujian hasil analisa ini, digunakan aplikasi toolbox matlab untuk tahap pengujian terhadap analisa kepada fuzzymatlabtoolbox, yang harus dilakukan setelah menjalankan aplikasi matlab adalah menggaktifkan toolbox fuzzy dengan cara mengetikkan fuzzy pada command line seperti gambar 7 dibawah ini.

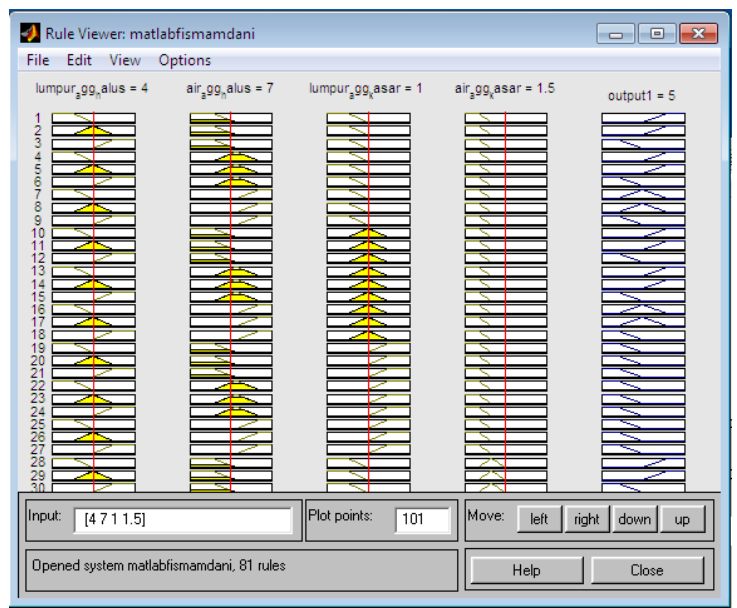

Gambar 7. Rule Viewer Metode Mamdani 


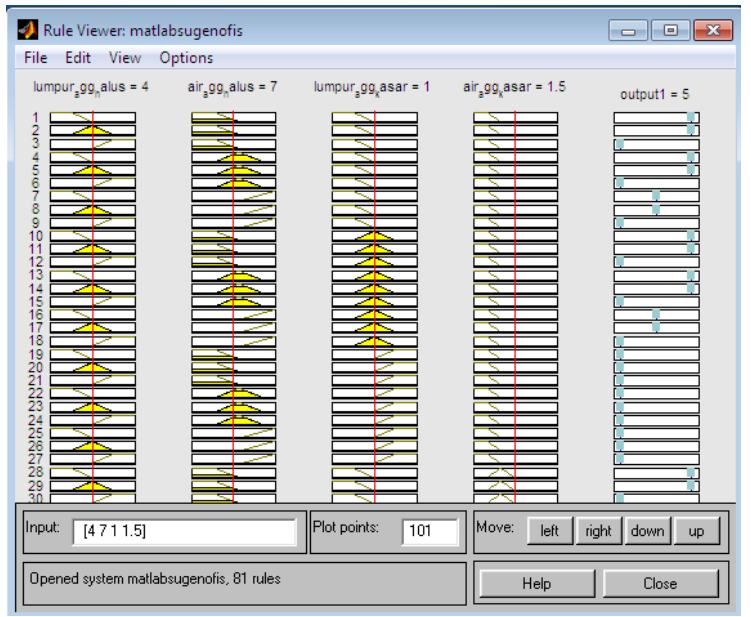

Gambar 8. Rule Viewer Metode Sugeno

\section{KESIMPULAN DAN SARAN}

Berdasarkan hasil penelitian yang dilakukan, dapat diambil beberapa kesimpulan, yaitu dengan menggunakan metode mamdani dan sugeno bisa dipakai dalam menentukan kualitas tetapi yang lebih direkomendasikan adalah metode Mamdani karena metode Mamdani hasil perhitunganya lebih mendekati hasil yang sebenarnya dibandingkan dengan sugeno.

\section{DAFTAR PUSTAKA}

[1] Shleeg, Aishalaa M. Ellabib, I. (2013) 'Comparison of Mamdani and Sugeno Fuzzy Interference Systems for the Breast Cancer Risk', International Journal of Computer, Electrical, Automation, Control and Information Engineering, 7(No. 10), pp. 695-699.

[2] Alfarisyi, M. I. and Amila, K. (2014) 'Rancangan Sistem Informasi Layanan Alumni Itenas Berbasis Web', Jurnal Online Institut Teknologi Nasional, 2(1), pp. 132-143.

[3] Ansari, G. A. (2012) 'Available Online at www.jgrcs.info A UML MODEL FOR MEASURING THE PERFORMANCE OF STUDENTS USING OBJECT ORIENTED APPROACH', 3(3), pp. 3-6.

[4] Artina, N. (no date) 'Sistem Informasi Penjualan Tiket Dan Paket Tour Berbasis Web Ada Cv . Four Brother Palembang'.

[5] Boissière, M., van Heist, M., Sheil, D., Basuki, I., Frazier, S., Ginting, U., Wan, M., Hariadi, B., Hariyadi, H. and Kristianto, H. D. (2004) 'Pentingnya sumberdaya alam bagi masyarakat lokal di daerah aliran sungai Mamberamo, Papua, dan implikasinya bagi konservasi', Journal of Tropical Ethnobiology Vol I, 2(2), pp. 76-95. Available at: http://www.cifor.org/mla/download/publication/konservasi_mamberamo.pdf.

[6] Dharwiyanti, S. and Wahono, R. S. (2003) 'Pengantar Unified Modeling LAnguage (UML)', IlmuKomputer.com, pp. 1-13. Available at: http://www.unej.ac.id/pdf/yanti-uml.pdf.

[7] Fahmy, R., Zaher, H. and Kandil, A. (2015) 'A Comparison between Fuzzy 
Inference Systems for Prediction ( with Application to Prices of Fund in Egypt )', International Journal of Computer Applications, 109(13), pp. 6-11. Available at: http://research.ijcaonline.org/volume109/number13/pxc3900604.pdf.

[8] Harmiyati, A. \& (2015) 'Perbandingan Nilai Kuat Tekan Beton Berdasarkan Beberapa Metode Persyaratan Penerimaan Beton di Indonesia', 15, pp. 65-87.

[9] Informasi, J. T., Yudihartanti, Y., Syukur, A., Wahono, R. S., Teknik, P., Universitas, I. and Nuswantoro, D. (2011) 'PENJADWALAN MATA KULIAH Permasalahan Pendekatan Konstruksi Hasil', 7, pp. 109-116.

[10] Jakimi, A. and Koutbi, M. El (2009) 'An Object-Oriented Approach to UML Scenarios Engineering and Code Generation', International Journal of Computer Theory and Engineering, 1(1), pp. 35-41. doi: 10.7763/IJCTE.2009.V1.6.

[11] Kaur, A. (2012) 'Application Of UML In Real-Time Embedded Systems', International Journal of Software Engineering \& Applications, 3(2), pp. 59-70. doi: 10.5121/ijsea.2012.3205.

[12] Kuo, M. S., Liang, G. S. and Huang, W. C. (2006) 'Extensions of the multicriteria analysis with pairwise comparison under a fuzzy environment', International Journal of Approximate Reasoning, 43(3), pp. 268-285. doi: 10.1016/j.ijar.2006.04.006.

[13] Lee, S. (2012) 'Unified Modeling Language ( UML ) for Database Systems and Computer Applications', International Journal of Database Theory and Application, 5(1), pp. 157-164.

[14] Masya, F. and Simanjuntak, F. M. (2012) 'Sistem Pelayanan Pengaduan Masyarakat Pada Divisi Humas', 2012(Snati), pp. 15-16.

[15] Matematika, P. S., Kristen, U. and Wacana, S. (2014) 'PENGGUNAAN METODE FUZZY MAMDANI DAN SUGENO KREDIT Studi Kasus: Pengambilan Keputusan Kredit PT . Kandimadu Arta Cabang Salatiga'.

[16] Math, N. S. J. and Mirkovi, M. (2008) 'MODELLING AND IMPLEMENTATION OF THE', 38(1), pp. 43-57.

[17] Mokhati.F (2009) 'Generating Maude Specifications From', 8(2), pp. 119-136.

[18] Prediksi, A., Persediaan, K., Pada, O., Farmasi, I., Sakit, R., Jember, D. K. T., Double, M. M., Smoothing, E., Ayu, R., Sari, A., Studi, P., Informasi, S. and Jember, U. (2015) 'Digital Repository Universitas Jember Digital Repository Universitas Jember'.

[19] Pt, P. and Jaya, K. (2007) 'Karyawan Dengan Metode Barcode'.

[20] Purnama, P. A. (2012) 'Aplikasi Sistem Inferensi Fuzzy Sugeno Dalam Memprediksi Laju Inflasi ( Studi Kasus Pada Data Inflasi Indonesia Dan Bali )', (1), pp. 5-8.

[21] Rachman, M. and Semarang, U. N. (2012) 'Konservasi nilai dan warisan budaya', 1(1), pp. 30-39.

[22] Saepullah, A. (2015) 'Comparative Analysis of Mamdani, Sugeno And Tsukamoto Method of Fuzzy Inference System for Air Conditioner Energy Saving', 1(2), pp. 143-147.

[23] Seminar, M. and Akhir, T. (no date) 'Perancangan Aplikasi Sistem Informasi Perumahan Dengan Menggunakan Pemrograman’, pp. 1-8.Seminar, M. and Akhir, T. (no date) 'Perancangan Aplikasi Sistem Informasi Perumahan Dengan Menggunakan Pemrograman', pp. 1-8.

[24] Solikin, F. (2013) 'Aplikasi logika Fuzzy Dalam Operasi Produksi Barang Menggunakan metode Mamdani dan Sugeno', 2013(Sentika).

[25] Su, F. U. Z. Z. Y., Pada, G. E. N. O. and Xyz, P. T. (2013) 'Perbandingan Produksi Kopi Optimum Antara Metode Fuzzy mamdai dengan Fuzzy Sugeno pada PT.XYZ, 
Rianto Samosir, Iryanto, Rosman Siregar', 1(6), pp. 517-527.

[26] Sumarta, T., Siswoyo, B. and Juhana, N. (no date) 'Perancangan Model Berorientasi Objek Menggunakan Unified Modeling Language (UML) Studi Kasus Sistem Pengolahan Parkir Pada PT. TRIKARYA ABADI', Elib.Unikom.Ac.Id, pp. 1-8

[27] Sunarya, U. (2015) 'Analisis Perbandingan Algoritma Logika Fuzzy Model Sugeno dan Mamdani untuk Pengukuran Kualitas Kolam Air Renang Berbasis Mikrokontroller'.

[28] Tribasuki, A. (2011) 'Cuti Karyawan Berbasis Web'.

[29] Utomo, S. D. (2008) 'Penanganan Pengaduan Masyarakat Mengenai Pelayanan Publik', 15, pp. 161-167.

[30] Van den Berg, J., Kaymak, U. and Van den Bergh, W. M. (2004) 'Financial markets analysis by using a probabilistic fuzzy modelling approach', International Journal of Approximate Reasoning, 35(3), pp. 291-305. doi: 10.1016/j.ijar.2003.08.007.

[31] Yoo, H. and Choi, B. (2015) 'Design of Simple-Structured Fuzzy Logic Systems for Segway-Type Mobile Robot', The International Journal of Fuzzy Logic and Intelligent Systems, 15(4), pp. 232-239. doi: 10.5391/IJFIS.2015.15.4.232.

[32] 'Rancang Bangun Portal E-Commerce Semarang-Handycraft Berorientasi Obyek Sinta Tridian Galih[1], Mustafid[2] , Aris Sugiharto2 Magister Sistem Informasi, Universitas Diponegoro' (no date). 